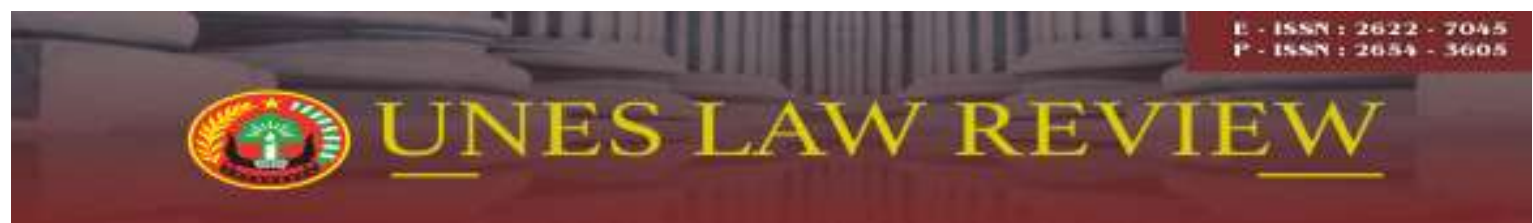

Email: uneslawreview@gmail.com

Online: http://review-unes.com/index.php/law

Volume 2, Issue 2, Desember 2019

\title{
PERAN BADAN MUSYAWARAH NAGARI SUNGAI SARIAK SEBAGAI PENGAWAS PENGGUNAAN ANGGARAN YANG BERSUMBER DARI DANA DESA
}

\author{
Titra Junaidi \\ Pemerintahan Kabupaten Padang Pariaman, Sumatera Barat, Indonesia \\ E-mail : titrajunaidi@gmail.com
}

\begin{abstract}
The Role of the Nagari Consultative Body is a form of democracy at the nagari level, Bamus functions to determine the nagari regulations together with the nagari government, to accommodate and channel the aspirations of the nagari community and to oversee the nagari financial management. Regional District of Padang Pariaman Number 05 of 2009 the role of Bamus has not been maximized in accommodating the aspirations of the community, the lack of socialization about development planning and supervision of the Nagari Government and BAMUS coordination in the meeting agenda is expected to play a more effective role in the future management of the nagari financial management. Based on the background description that has been conveyed How is the Role of Bamus in supervising the implementation of the Nagari Government in Nagari Sungai Sariak Kecamatn VII koto Sungai Sariak and What are the obstacles faced by Bamus in supervising the Nagari Government and the efforts made in Nagari Sungai Sariak District VII Koto Sariak. River The research method used is descriptive analytical method. Descriptive research analyzes and presents data and facts systematically so that they can be more easily understood and concluded. This study aims to determine how the role of the Nagari Consultative Body as a Supervisor of the Use of Budgets sourced from Village Funds, especially in the Sariari Nagari Sungai VII, Koto Sungai Sariak District. The results of the research in Nagari, have concluded that the Nagari Consultative Body has not worked optimally in accordance with the role of BAMUS in the Regional Regulation of Padang Pariaman District Number 05 of 2009. The Nagari Musaraharah Agency (Bamus) in carrying out the Nagari fund supervision function has not been maximized, this has occurred. because the Nagari Deliberation Board (Bamus) in carrying out its duties Bamus experienced several obstacles The Sariak River Nagari Deliberation Board (Bamus) was expected to be able to carry out its supervisory function and Bamus's role in the Nagari deliberation to the maximum and be able to communicate well as a partner of the ngari government.
\end{abstract}

Kata Kunci: Badan Musyawarah, Penggunaan Anggara, Dana Desa 


\section{PENDAHULUAN}

Pasal 18 Undang -Undang Dasar Republik Indonesia Tahun 1945 yang telah diamandemen dan ditambahkan menjadi pasal 18, 18A, dan 18B memberikan dasar dalam penyelenggaraan desentralisasi. Negara Kesatuan Republik Indonesia dibagi atas daerahdaerah provinsi, dan daerah provinsi itu dibagi atas kabupaten dan kota yang masingmasing mempunyai pemerintahan daerah. Nagari merupakan kesatuan masyarakat hukum yang memiliki batas wilayah yang berwenang untuk mengatur dan mengurus urusan pemerintahan serta kepentingan masyarakat setempat berdasarkan prakarsa masyarakat, hak asal usul, dan/ atau hak tradisional yang diakui dan dihormati dalam sistem pemerintahan Negara kesatuan Rebublik Indonesia sebagai mana tertuang pada Pasal 1 ayat 1 Undang-Undang Nomor 6 tahun 2014.

Pemerintah desa adalah penyelenggara urusan pemerintahan dan kepentingan masyarakat setempat dalam sistem pemerintahan Negara Kesatruan Republik Indonesia (NKRI) Pasal 1 ayat 2 Undang-Undang Nomor 6 tahun 2014. Penyelenggara pemerintah desa merupakan sub sistem dari penyelenggaraan pemerintahan, sehingga Nagari memiliki kewenangan untuk mengatur dan mengurus kepentingan masyarakatnya.

Perkembangan otonomi daerah, memunculkan ide untuk mengembalikan sistem pemerintahan di Sumatera Barat kepada sistem pemerintahan nagari. Di daerah Sumatera Barat timbul suatu istilah yang dikenal dengan "babaliak ka nagari". Hal ini ditindak lanjuti oleh pemerintah provinsi Sumatera Barat dengan mengeluarkan Peraturan Daerah Nomor 9 Tahun 2000 tentang Pemerintahan Nagari. Dalam Perda ini dinyatakan bahwa pemerintahan terendah di Sumatera Barat adalah nagari, yang kemudian direvisi dengan Peraturan Daerah Nomor 2 Tahun 2007 bahwa nagari adalah kesatuan masyarakat hukum adat yang memiliki batas-batas wilayah tertentu, dan berwenang untuk mengatur dan mengurus kepentingan masyarakat setempat berdasarkan filosofi adat Minangkabau (Adat Basandi Syarak, syarak Basandi Kitabullah) dan atau berdasarkan asal usul dan adat istiadat setempat dalam wilayah Provinsi Sumatera Barat.

Perkembangan politik di Indonesia senantiasa mengalami kemajuan dari orde lama sampai sekarang. Kebijakan politik maupun pemerintahan orde lama lebih menekankan pada keleluasaan sentralisasi, dimana semua urusan diserahkan sepenuhnya ke pusat. Hal ini tentunya belum sepenuhnya terdapat adanya otonomi daerah. Baik di tingkat desa 
sampai tingkat provinsi. Masing-masing daerah sepenuhnya disetir oleh pemerintah. Di tingkat desa misalnya, kebijakan kebijakan pemerintah melalui perangkat desa merupakan kebijakan atasannya dari Camat, Bupati, Gubernur, sampai ke pusat, sehingga perangkat desa belum memaksimalkan keadaan desa yang dipimpinnya.

Munculnya Undang-Undang No. 32 tahun 2004 tentang Pemerintah Daerah dan di sempurnakan Undang -Undang Nomor 23 tahun 2014 Tentang Pemerintahan Daerah. Semangat untuk mengembalikan hak - hak istimewa daerah dapat dibaca di dalam Pasal 1Angka (6 ) yaitu Otonomi Daerah adalah hak, wewenang, dan kewajiban Daerah Otonom untuk mengatur dan mengurus sendiri urusan Pemerintah dan kepentingan masyarakat setempat dalam sistem Negara Republik Indonesia.”

Pada Undang - Undang Nomor 6 Tahun 2014 Tentang Desa pada Pasal 8 Angka (2) "Pembentukan Desa ditetapkan dengan Peraturan Daerah Kabupaten atau Kota dengan mempertimbangkan prakarsa masyarakat Desa, asal usul, adat istiadat, kondisi sosial budaya masyarakat Desa serta kemampuan dan potensi Desa pada dasarnya masing - masing daerah mempunyai arti yang berbeda, Salah satu nama Desa di Provinsi Sumatera Barat adalah Nagari . Pada Provinsi Sumatera Barat. Nagari adalah pembagian wilayah administratif sesudah Kecamatan, istilah Nagari merupakan pergantian Desa yang digunakan di Provinsi dalam hal tersebut Pemerintah Sumatera Barat merevisi Peraturan tersebut yang dimana lahir lah Peraturan Daerah Provinsi Sumatera Barat Nomor 2 Tahun 2007 Tentang Pokok - Pokok Pemerintahan Nagari yang sebagaimana acuan bagi Pemerintahan Nagari untuk menjalankan sistem Pemerintahan Negara Republik Indonesia.

Secara historis pemerintahan nagari merupakan sebuah pemerintahan tradisional yang diperintah oleh penghulu-penghulu suku yang memiliki kewenangan yang sama derajatnya yang tergabung dalam sebuah kerapatan adat. Sistem pemerintahan nagari ini sudah dijalankan sejak dahulu oleh masyarakat Minangkabau. Pada tahun 1979 melalui Undang-Undang Nomor 5 Tahun 1979 Tentang Pemerintahan Desa, pemerintah menyeragamkan sistem pemerintahan terendah di Indonesia menjadi desa, semenjak tanggal 01 Agustus 1983 nagari yang pada awalnya merupakan sistem pemerintahan terendah di Sumatera Barat berubag menjadi desa yang merupakan sistem pemerintahan budaya Jawa. 
Dalam menjalankan sistem pemerintahan nagari, nagari dipimpin oleh Wali Nagari yang dipilih secara demokratis oleh masyarakat di nagari tersebut. Dalam melaksanakan pemerintahan nagari Wali Nagari dibantu oleh staff dan kaur serta lembaga- lembaga yang telah dipilih sesuai dengan musyawarah dan mufakat dari masyarakat nagari.

Berdasarkan Peraturan Daerah Kabupaten Padang Pariaman Nomor 05 Tahun 2009 Tentang Pemerintahan Nagari, Badan Musyawarah Nagari (BAMUS Nagari) merupakan unsur pelaksana sistem pemerintahan nagari. BAMUS Nagari berfungsi menetapkan peraturan nagari bersama waki nagari, menampung dan menyalurkan aspirasi masyarakat. Anggota BAMUS Nagari terdiri dari unsur niniak mamak, alim ulama, cadiak pandai, bundo kanduang serta generasi muda yang ada di nagari. Jumlah keanggotaan BAMUS Nagari ini berjumlah ganjil, paling sedikit lima orang dan paing banyak sebelas orang sesuai dengan luas wilayah nagari, jumlah penduduk dan kemampuan keuangan nagari.

Pemerintah Nagari dan Badan Musyawarah Nagari adalah dua lembaga pemerintahan yang tidak bisa dilepaskan dalam suatu wilayah terkecil. Dua lembaga ini saling berkaitan antara satu dan yang lain dalam menjalankan roda pemerintahan. Kedudukan Badan Musyawarah Nagari (BAMUS Nagari) di Nagari Sungai Sariak adalah sebagai pendamping Wali Nagari dalam menyerap aspirasi rakyat, tetapi dalam pelaksanaan penerapan tugas dan wewenangnya.Pada dasarnya Wali Nagari beserta Badan Musyawarah Nagari (BAMUS Nagari) sebagai pejabat pemerintahan di nagari harus dapat menjalankan tugasnya dengan baik untuk membina dan memakmurkan masyarakat yang berada dibawah kepemimpinannya.

Berdasarkan uraian latar belakang yang sudah disampaikan maka Penulis tertarik untuk membahas penelitian tesis tentang." Peran Badan Musyawarah Nagari Sebagai Pengawas Pengunaan Angggaran Yang Bersumber Dari Dana Desa (Studi di Nagari Sungai Sariak)

\section{METODE PENELITIAN}

Penelitian ini bersifat deskriptif-analitis, yaitu penelitian yang menggambarkan atau melukiskan secara faktual objek penelitian secara sistematis yang kemudian dianalisis mengenai analisis yurudis kualitatif. Berdasarkan data-data yang telah berhasil 
dikumpulkan, baik data primer maupun data sekunder, dapat ditarik suatu kesimpulan untuk dianalisa. Secara kualitatif yaitu dengan mengelompokan data menurut aspek-aspek yang diteliti tanpa menggunakan angka-angka atau dengan kata lain data muncul berwujud kata-kata,dengan bertitik pangkal pada hukum atau norma yang berlaku.

\section{HASIL PENELITIAN DAN PEMBAHASAN}

\section{HASIL PENELITIAN}

\section{Gambaran Lokasi Penelitian}

Kecamatan VII Koto Sungai Sariak merupakan salah satu dari 17 Kecamatan yang ada di Kabupaten Paadang Pariaman, Kecamatan VII Koto Sungai Sariak memiliki 9 (sembilan ) Nagari dan 69 (empat puluh dua) Korong (setingkat Dusun atau RW) dengan luas dan jumlah korong masing-masing, yaitu

1. Nagari Sungai sariak(nagari induk) 4 korong.

2. Nagari Lareh nan panjang 6 korong.

3. Nagari Bisati Sungai sariak 5 korong.

4. Nagari Limpato Sungai sariak 7 korong.

5. Nagari Ambuang Kapua Sungai sariak 4 Korong.

6. Nagari Lurah Ampalu (, 5 Korong)

7. Nagari Balah Aia ( 9 Korong)

8. Nagari Lareh Nan Panjang ( 9 Korong)

9. Nagari Balah Timur ( 6 Korong )

\section{Peran Badan Musyawarah Nagari Dalam Pengelolaan Dana Desa}

Badan Permusyawaratan Nagari adalah sebagai perwujudan demokrasi dalam penyelengara pemerintah desa menampung, menyalurkan, aspirasi masyarakat badan permusyawaratan yang terdiri atas pemuka-pemuka masyarakat yang ada di desa berfungsi mengayomi adat istiadat, membuat peraturan desa, serta melakukan pengawasan langsung terhadap penyelenggaraan pemerintah Nagari.

Berdasarkan ketentuan diatas kedudukan, fungsi, wewenag dan tugas Bamus dalam penyelenggaraan pemerintahan desa sangatlah penting. Sebagai satu-satunya lembaga perwakilan yang berfungsi sebagai saluran aspirasi utama warga desa tidak hanya 
berfungsi sebagai badan legislasi, melainkan sebagai arsitek perubahan dan pembangunan Nagari.

Badan Permusyawaratan nagai berkedudukan sabagai unsur penyelenggara pemerintah nagari sebagai berikut :

1. Anggota Bamus Nagari adalah wakil dari penduduk Nagari, berdasarkan keterwakilan wilayah yang ditetapkan dengan cara musyawarah dan mufakat.

2. Anggota Bsmus nagari adalah wakil dari penduduk nagari, berdasarkan keterwakilan wilayah yang ditetapkan dengan cara musyawarah dan mufakat

3. Anggota Bamus terdiri ketua rukun warga, pemangku adat, golongan profesi, pemuka agama dan tokohatau pemuka mayarakat lainnya.

4. Masa jabatan anggota Bamus adalah 6 (enama) tahun dan dapat diangkat/diusulkan kembali untuk 1 (satu) kali masa jabatan berikutnya:

5. Jumlah anggota Bamus berjumlah ganjil, minimal 5 (lima) orang maksimal 11 (sebelas) orang berdasarkan ( Luas Wilayah . Jumlah Penduduk, dan Kemampuan keuangan Nagri )

6. Peresmian anggota Bamus ditetapkan dengan Keputusan Bupati/walikota:

7. Sebelum memangku jabatannya, anggota Bamus mengucapkan sumpah/janji secara bersama-sama di hadapan masyarakat dan dipandu oleh Bupati/Walikota.

8. Pimpinan Bamus terdiri dari;

a. Ketua (1 orang)

b. Wakil Ketua (1 orang)

c. Sekretaris (1 orang).

\section{PEMBAHASAN}

\section{Peran Bamus Dalam Pelaksanaan Pengawasan Penyelengaraan Pemerintahan Nagari di Sungai Sariak}

Peran Badan Permusyawaratan Nagari ( Bamus ) atau dengan nama lain adalah lembaga yang melakukan fungsi pemerintahan yang anggotanya merupakan wakil dari penduduk ngari berdasarkan keterwakilan wilayah dan di tetapkan secara demokratis. Badan Permusyawaratan Nagari merupakan badan permusyawaratan di tingkat nagari yang turut membahas dan menyepakati berbagai kebijakan dalam Pemerintahan Nagari .

Berdasarkan Undang-Undang Republik Indonesia Nomor 23 Tahun 2014 tentang Pemerintahan Daerah dalam penjelasannya menyatakan bahwa kedudukan Badan Permusyawaratan Ngari adalah sebagai mitra kerja Pemerintah Nagri dalam memberdayakan masyarakat nagari . Sebagai mitra kerja Pemerintah Nagari, keberadaan 
Bamus diharapkan mampu menutup berbagai apa yang menjadi kelemahan dan kekurangan Pemerintah Nagari yang pelaksanaannya tidak boleh keluar dari koridor pemberdayaan masyarakat nagari . Dengan hadirnya Badan Permusyawaratan Nagari (Bamus ) diharapkan mampu memberikan trobosan dalam pemberdayaan dan pencerdasan kepada masyarakat nagari, dalam membangun kemandirian, kreativitas, mengatur rumah tangga sendiri dan membuka ruang bagi masyarakat nagari untuk ikut serta dalam proses penyelenggaraan pemerintahan dan pembangunan ngari. Sehingga apa yang selama ini yang didamba-dambakan oleh masyarakat Desa untuk memiliki otonomi dan integritas sebagai kesatuan masyarakat serta kedaulatan dan hak wilayahnya dalam menjalankan pemerintahan secara otonomi untuk menciptakan kemakmuran dapat tercapai.

\section{Peran Bamus}

Arti penting dan prospektif pembentukan Badan Permusyawaratan nagari (Bamus) adalah: Pertama, kehadirannya merupakan wahana bagi kehidupan berdemokrasi dinagari . Kedua, sebagai jawaban kongkrit ketidakberdayaan institusiinstitusi demokrasi formal di perdesaan. Ketiga, mendorong terciptanya proses penyelenggaraan pemerintahan nagari yang demokratis, akuntabilitas, trasnparasi, kejujuran, kesetaraan dalam pelayanan, partisipasi masyarakat, konstitusional berjalan diatas aturan yang ada. Keempat, berkurangnya monopoli kekuasaan politik yang selama ini sentralistik (Wali Nagari selama ini sebagai penguasa tunggal Kelima, menumbuhkan kesadaran baru kepada warga nagari akan hak-hak tanggungjawab sebagai warga Negara dalam proses penyelenggaraan Pemerintahan Desa. Keenam, merupakan pengalaman berharga bagi pemerintah bahwa kebijakan selama ini (mengenai Nagari) ada kekeliruan yang dapat mematikan inisiatif dan kreasi masyarakat. Berkaitan dengan Badan Permusyawarataan Nagari . Bamus sendiri adalah sebagai mitra kerja pemerintah Nagari yang melaksanakan tugasnya dengan baik, disini terlihat adanya suatu kerja sama antara Bamus dan pemerintah nagari yang saling menghormati, bantu membantu, saling mengisi guna tercapainya penyelenggaraan pemerintah desa yang efesien, efektif serta tercapainya kemakmuran desa.

\section{Mekanisme Bamus dalam Mengawasi Dana Desa}

Telah begitu banyak peraturan yang mengatur tentang Badan Permusyawaratan nagari tanpa implementasi yang jelas menjadikan hal yang menarik untuk mengetahui bagaimana sebenarnya kinerja Bamus itu, apakah benar-benar membantu pemerintah desa dalam penyelenggaraan pemerintah atau hanya menjadi simbol demokrasi tanpa implementasi, atau malah menimbulkan masalah yang tidak perlu, yang hanya akan menghabiskan energi yangsesungguhnya lebih dibutuhkan oleh masyarakat desa untuk melepaskan diri dari jerat kemiskinan dan krisis ekonomi.

Pengawasan terhadap pelaksanaan pemerintah merupakan salah satu alasan terpenting mengapa Bamus perlu dibentuk. Pengawasan oleh Bamus terhadap pelaksanaan pemerintah nagri Sungai Sariak yang dipimpin oleh wali nagri merupakan tugas Bamus . Upaya pengawasan dimaksud untuk mengurangi adanya penyelewengan 
atas kewenangan dan keuangan desa dalam penyelenggaraan pemerintah desa. namun dalam skripsi ini lebih menekankan tentang peran Bamus dalam mengawasi dana nagari.

Dana desa adalah dana yang bersumber dari Anggaran Pendapatan Belanja Negara (APBN) yang diperuntuhkan untuk nagari, yang ditransfer melalui anggaran belanja daerah kabupaten atau kota. Dana desa sendiri digunakan untuk membiayai penyelenggaraan pemerintah, pelaksanaan pembangunan, pembinaan kemasyarakatan, dan pemberdaya masyarakat nagari.

\section{Proses Pengawasan Bamus}

Karena dana desa yang bersumber dari pemerintah jumlahnya cukup besar maka besar maka diperlukan mekanisme kontrol langsung dari Bamus atau masyarakat untuk mengawasi penggunaan dana desa tersebut agar dana tersebut dipergunakan sesuai dengan peruntukkannya untuk meningkatkan kesejahteraan masyarakat.

Di nagari Sungai Sariak Bamus bukan hanya sebagai lembaga yang mengawasi atau sebagai penyalur aspirasi masyarakat desa tatapi juga sebagai partner kerja yang bersinergi satu sama lain. Hubungan antara Bamus dengan Pemerintah nagari terbilang cukup bagus karena apapun kinerja wali nagari yang berkaitan tentang pembangunan, pengeluaaran anggaran nagari dan lain -lain tak lepas pula kerja sama atau saling memintah pedapat tentang apa yang akan dikerjakan pemerintah nagari.

Jadi proses pengawasan terhapat pemerintah desa itu sedikit meringankan kinerja Bamus karna di nagari Sungai Sariak bukan hanya Bamus yang menjadi sistem pengawasan tetapi semua sektor, baik itu lembaga masyarakat lembaga pemuda atau masyaarakat itu sendiri.Biasanya Bamus suadah mengetahui berapa dana yang masuk ke nagari setelah dana masuk ke nagari Bamus melakukan MUSREMBANG (musyawara perencanaan pembangunan) tingkat desa lalu dibagi korong jadi apa-apa saja hal yang diprioritaskan sudah terkaper kesemua sektor. Tak lepas pula dari tanggung jawab Bamus. Bamus biasanya melakukan pertemuan sebulan sekali atau tidak menentu dengan pemerintah desa yang membahas tentang anggaran dana desa dan dihadiri oleh tokoh-tokoh masyarakat.

\section{Hambatan -hambatan dan Upaya Yang Dilakukan Dalam Peran Bamus Sebagai Pengawas Pengunaan Angggaran}

Badan Permusyawaratan nagari merupakan lembaga perwakilan nagari yang memiliki fungsi dan tugas. Salah satu tugas dan fungsi dari Badan Permusyawaratan nagari adalah fungsi pengawasan, dalam menjalankan tugas dan fungsi tersebut, Badan Permusyawaratan nagari tidak terlepas dari suatu permasalahan. Adapun permasalahan yang dihadapi oleh Badan Permusyawaratan nagari adalah pengalokasian dana nagari yang hanya mencakup bidang pembangunan jalan dan kesehatan, serta pelaksanaan fungsi Badan Permusyawaratan nagari dalam pengawasan dana nagara di beberapa bidang yang belum terlaksana. 
Dalam Sistem Pemerintahan daerah pada saat ini pemerintah telah memberikan pada masyarakat peluang untuk lebih bisa kreatif dan bijaksanan dalam membangun nagari mereka sendiri, dan kita sadar di Minangkabau ini dahulunya telah mempunyai sistem pemerintahan yang dikenal dengan pemerintahan nagari, dalam menjalakab pemerintah nagari dipimpin oleh seorang yang dinamakan wali nagari yang dipilih langsung oleh masyrakat, namun dalam proses pemerintahan nagari masalah yang ada hambatan hambatan antra lain sebagai berikut;

1. Perbedaan pandangan antara Badan Musyawarah Nangari ( Bamus ) dengan pemerintah Nagari merupakan salah satu hambatan dalam hubungan antara Badan Musyawarah Nagari ( Bamus ) dan pemerintah nagari, karena dalam setiap pengembilan kebijakan oleh pemerintah nagari harus dikonsultasikan dengan Badan Musyawarah Nagari (Bamus ) maka tampa persetujuan Badan Musyawarah Nagari ( Bamus ) kebijakan tersebut tidak dikeluarkan .

2. Tidak kepercayaan juga salah satu hambatan Badan Musyarawah Nagari ( Bamus ) yang memiliki kewenangan mengali, menghimpun dan menyalurkan aspirasi masyarakat dapat mennyatakan tidak percaya terhadap pemerintah nagari sepanjang nasyarakat nagari menghendaki demian, akan tepai di sisi sebaliknya pemerintah nagari dapat juga tidak percaya apakah hal tersebut murni dari masyarakat atau tidak, dan apabila terjadi masalah yang lain yaitu tarik ulur kewenangn ,Badan Musyawarah Nagrai ( bamus ) yang berwenang mengusulkan pengangkatan atau pemberhentian wali nagari. Apabila terjadi pertentangan antaran Badan Musyawarah nagari ( Bamus ) deng wali nagari dapat mengusulkan pemberhentian wali ngari teresebut.

3. Dari hasil penelitian Pemerintah Nagari Sungai Sariak sebagaimna dikemukan diatas, jelas bahawa seorang ninik mamak (anggota) atau pengahulu mempunyai peranan penting dan fungsinya banyak sekali. Karena disamping pimpinsn di dalam suku yang mengatur anak kemenakannya juga sebagai pengetara dan ikut membantu penyelengaaran pemerintahan nagari, tentu dalam melaksakan kontrol sosial kepada pemerintahan sangat susah dilaksanakan

\section{Upaya Penyelenngaraan Pemerintahan Nagari}

1. Perbedaan pandangan antara Badan Musyawarah Nagari (Bamas) dengan pemerintah nagari dapat diatasi dengan menyamakan visi dan misi , bahwa keduanya memiliki tujuan yang sama yaitu untuk kemajuan nagari , baik Badan Musyawarah Nagari ( Bamus ) maupun pemerintah nagari harus lebih sering duduk bersama untuk membicarakan masalah -masalah yang ada dan mengambil kebijakan yang tepat.

2. Ketidak percayaan dapat diatasi dengan menghindari saling curika mengcurigai antar penyelenggara pemerintah nagari., Sealain itu juga baik Badan Musyawarah Nagari (Bamaus ) maupun pemerintah nagari harus menunjukan kinerja yang baik agar masyarakat nagari percaya kepada kedua lembaga tersebut. Tarik ulur kewenangan dapat diatasi antara kedua lembaga, sehinggga tidak ada alahan bagi masing-m,asing lembaga untuk saling menjatuhan. Sealain itu pemerintah nagari juaga harus leih berkoodinasi. 
3. Sebaiknya ninik mamak Penghulu ( anggota KAN ) tidak teerlebat dalam pemerintah nagari sebaiknya ninik mamak ( anggota KAN ) sebagai kontrol sosial dalam penyelenggaraan pemerintahan nagari yang efektif

\section{PENUTUP}

Peran Badan Musyawarah Nagarai (Bamaus) Nagari Sungai Sariak dalam mekanisme fungsi pengawasan dana desa dilaksanakan dari tahap perencanaan, pelaksanaan kegiatan dan pertanggungjawaban. Pada tahap perencanaan, peran Badan Musyawarah Nagari (Bamus) dapat dilihat dari penyampaian aspirasi dari masyarakat dan juga pengesahan yang dilakukan oleh Badan Musyawarah bersama dengan wali nagari. Tanpa adanya persetujuan dari Bamus, RAPBDes tidak dapat dijadikan APBDes untuk digunakan sebagai aturan desa. Tahap selanjutnya adalah tahap pelaksanaan, pemerintah Nagari Sungai Sariak tidak dapat melaksanakan kegiatan tanapa adanya peran dari anggota Badan Musyawarah Nagari ( Bamus ), hal ini terjadi karena setiap kegiatan yang akan dilaksanakan oleh pemerintah desa harus melalui persetujuan dari anggota Badan Musyawarah Nagari (Bamus) dan Wali Nagari , pada tahap ini Badan Musyawarah Nagari (Bamus) mengawasi semua pelaksanaan kegiatan pembangunan kegiatan kesehatan yang disesuaikan denagan APBDes. Tahap terakhir pertanggungjawaban, dalam penyusunan laporan pertanggungjawaban peran Badan Musyawarah Nagari (Banus) sangat dibutuhkan, karena Badan Musyawarah Nagari akan memberikan persetujuan laporan pertanggungjawaban dari pemerintah jika laporan tersebut sudah sesuai dengan APBDes dan juga hasil dari kegiatan tersebut. Tanpa adanya peran dari Badan Musyawarah Nagari, pemerintah Sungai Sariak melaksanakan kegitan tidak dapat berjalan.

Badan musyawaarah Nagari (Bamus) dalam melaksanakan fungsi pengawasan dana nagari berjalan belum maksimal, hal ini terjadi karena Badan Musyawarah Nagari (Bamus) dalam melaksanakan tugasnya Bamus mengalami beberapa hambatan. Hambatan dari dalam lembaga BPD yaitu kuranganya informasi yang diperoleh Bamus dari pusat, aturan yang belum turun, serta belum menguasai peraturan-peraturan dan undang-undang. Sedangkan hambatan dari dalam lembaga itu . sendiri yakni kurangnya komunikasi dengan pemerintah nagari 


\section{DAFTAR PUSTAKA}

\section{Buku Teks :}

Marbun, B.N. DPRD Pertumbuhan, Masalah, dan Masa Depannya. Jakarta: P.T..Gelora Aksara Pratama. 1994.

Ridwan HR. Hukum Administrasi Negara Jakarta . Raja Grafindo 2006.

\section{Peraturan Undang-Undang :}

Undang-Undang Dasar Republik Indonesia Tahun 1945

Undang-Undang Nomor 22 Tahun 1999 Tentang Otonomi Daerah

Undang-Undang Nomor 32 Tahun 2004 Tentang Otonomi Daerah

Undang-Undang Nomor 6 Tahun 2014 Tentang Desa.

Undang-Undang Nomor 23 Tahun 2014 Tentang Pemerintahan Daerah.

Peraturan Pemerintah Nomor 43 Tahun 2014 Tentang Peraturan Pelaksanaan Undang Undang Nomor 62014 tentang Desa

Peraturan Pemerintah Nomor 60 Tahun 2014 Tentang Dana Desa

Peraturan Daerah Provinsi Sumatra Barat Nomor 2 Tahun 2007 Tentang Pokok - Pokok Pemerintahan Nagari.

Peraturan Daerah Kabupaten Padang Pariaman Nomor 05 Tahun 2009 Tentang Pemerintahan Nagari.

Peraturan Daerah Kabupaten Padang Paraiaman Nomor 41 Tahun 2018 Tentang Penetapan Rincian dana Desa setiap Nagari di Kabuapaten Padang Pariaman

\section{Jurnal Karya Imiah}

Nora, Lidia. Partisipasi Masyarakat Nagari Mewujudkan Format Penyelenggaraan Pemerintahan Nagari Yang Efektif dan Efisien di Sumatera Barat. Padang: Universitas Negeri Padang 2010.

R, Evayanti Desi Peran BAMUS dalam Menjalankan Fungsi Pengawasan Terhadap Wali . Universitas Andalas. Skripsi tidak diterbitkan. 2011.

Yaserdi. 2003. Alua Pasambahan Di Minangkabau. Payobada: Limbago Adat Payobada XII Kampuang. 